\title{
OS FASTOS: FESTAS E RITUAIS PAGÃOS DEDICADOS À DEUSA ANA PERENA
}

\author{
Eliana da Cunha Lopes (FGS) \\ elianalatim@yahoo.com.br
}

\begin{abstract}
As obras de Ovídio foram lidas e apreciadas em todos os tempos. Na Idade Média, muito embora fosse um autor pagão, tivesse escrito sobre mito e deuses e pregado comportamento censurado pela ética do Cristianismo, Ovídio figurou nas "listas" de autores cuja leitura era "permitida", a partir do século XII.
\end{abstract}

(CORREIA \& FERREIRA, 1992, p. 11).

O presente artigo tem por objetivo mostrar as festas populares e os rituais dedicados à deusa Ana Perena. Utilizaremos, particularmente, os versos 523-544, retirados do terceiro livro dos Fastos, poema escrito pelo sulmonense Públio Ovídio Nasão (Publius Ovidius Naso), na maturidade. Os versos foram elaborados em dísticos e elegíacos (hexâmetro e pentâmetro) e neste ritmo marcam a euforia e a alegria da plebe, por causa do vinho, nos idos de março, quando festejam, não longe do rio Tibre, a festa em louvor à deusa.

\section{Os Fastos}

Os Fastos são um calendário nacional, onde são descritos os cultos e as festas religiosas dos seis primeiros meses do ano. Esta obra, pertence à segunda fase da vida do poeta, foi escrita em dísticos elegíacos. Dividem-se em seis livros, cada um deles dedicado a um mês do calendário romano, incluindo apenas os seus primeiros meses do ano, de janeiro a junho.

Fasti, -orum (m. pl.), em latim, significa calendário. Inicialmente estes Fasti marcavam apenas os dias festivos dedicados aos deuses mitológicos. Na obra de Ovídio, entretanto, o calendário assume uma característica mais abrangente. Nele serão anexadas, também, datas nacionais, isto é, datas festivas que o Senado incluiu no calendário, a fim de comemorar os aniversários de vitórias de Júlio 
César e as vitórias de seu filho adotivo, o Imperador Augusto. Deste modo, os Fastos vão abarcar tanto os registros das festas religiosas quanto das festas cívicas, constituindo-se num calendário poéticoreligioso-romano escrito em dísticos elegíacos. E, a partir desta data, iniciam-se os relatos das festas dedicadas aos homens ilustres de Roma.

O primeiro livro da obra refere-se ao mês de janeiro, Ianuarius mensis, em latim. É consagrado a Jano, o deus protetor de todos os começos, representado com dois rostos: um voltado para o passado e outro para o futuro. As grandes festas dedicadas a Jano, as Agonais (Agonalia), eram comemoradas, com a oferenda de grandes sacrifícios, no dia 9 de janeiro (Ov. F. 1, 317-9).

Quatuor adde dies ductis ex ordine Nonis;

Janus Agonali luce piandus erit.

Nominis esse potes, succinctus causa minister,

(Acrescenta quatro dias às Nonas contadas em ordem; no dia das Agonais, Jano deverá ser homenageado com sacrifícios. Ó ministro de roupa arregaçada, tu podes ser a causa do Nome).

Segundo Pierre Grimal (2000, p. 258),

Jano é um dos mais antigos deuses do panteão romano. É representado com dois rostos que se opõem um, olhando para frente, outro para trás. As lendas sobre Jano são unicamente romanas e ligadas às das origens da cidade.

Significava, assim, que Jano é um deus que conhecia tudo; aqueles fatos ocorridos no passado e os que haveriam de acontecer.

O poema é dedicado a Germânico, sobrinho do Imperador Tibério, famoso por suas campanhas militares sobre os povos germânicos.

O segundo livro refere-se a fevereiro, em latim, Februarius mensis, que é o mês reservado às cerimônias de purificação e expiação denominadas Februa. Não é dedicado especialmente a um deus. Essas cerimônias, em latim, chamavam-se februa, -orum (n. pl ). -, festividade religiosa de purificação e expiação celebrada no dia 15 de fevereiro: purificação; cerimônia expiatória; daí februarius mensis o mês das purificações. (Ov. , F. 2, 19).

Februa Romani dixere piamina patres: 


\section{FACULDADE dE FoRMAÇÃO de PROFESSORES} februa).

(Os antepassados romanos chamavam as cerimônias purificadoras de

Há, neste segundo livro, um prólogo dedicado a Augusto, o restaurador dos templos santos e fundador de novos templos (v. 59-66).

Caetera ne simili caderent labefacta ruina,

Cauit sacrati prouida cura ducis:

Sub quo delubris sentitur nulla senectus,

Nec satis est homines, obligat illi deos.

Templorum positor, templorum sancte repostor,

Sit Superis, opto, mutua cura tui:

Dent tibi coelestes, quot tu coelestibus annos,

Proque tua maneant in statione domo.

(O cuidado providencial do chefe sagrado providenciou para que os demais não caíssem destruídos por semelhante ruína. Sob o qual nenhuma velhice é sentida pelos templos. Não é bastante que favoreça os homens, ele também beneficia os deuses. Eu desejo ,ò restaurador dos templos, ó santo fundador dos templos, que os deuses superiores te dispensem a mesma atenção que os deuses celestes te deem quantos anos tu deste aos deuses celestes e que eles permaneçam em tua casa em vigilância).

O terceiro livro, corpus deste trabalho, abrange o mês de março: Martius mensis. Martius, -a, -um, adj. De Marte, da guerra: guerreiro; do mês de março. Era o primeiro mês do antigo calendário romano. Segundo a tradição, Rômulo, o primeiro rei de Roma, organizou um calendário, o primeiro calendário romano, de natureza lunar (isto é, composto por dez meses) e resolveu homenagear seu pai mitológico - o deus Marte -, dando-lhe as honras deste mês. Esta homenagem engloba os versos 73 ao 76, com a fala de Rômulo em discurso direto.

\footnotetext{
Arbiter armorum, de cuius sanguine natus

Credor - et, ut credar, pignora certa dabo-

A te principium romano ducimus anno:

Primus de Pátrio nomine mensis eat.
}

(Ó Senhor das armas, de cujo sangue eu creio que nasci - e, para que seja assim considerado, darei para ti uma garantia certa - atribuímos a ti o princípio do ano romano: que o primeiro mês venha do nome de meu pai).

$\mathrm{O}$ ano primitivo dos romanos começava em março porque nesta época ocorria, no hemisfério norte, onde se situa a cidade de Roma, o desabrochar da primavera que vai eclodir no mês seguinte. Marte é o deus romano identificado com o deus Ares helênico. Os meses de janeiro e fevereiro, do atual calendário, foram criados por 
Numa Pompílio, que percebeu que não havia coincidências entre os meses e as colheitas efetuadas.

Deve-se acrescentar às datas deste mês, o dia 15 de março, data do assassinato de Júlio César, no Senado. O calendário romano registra neste dia a sua morte e apoteose, ou seja, a passagem da natureza humana para a divina de Júlio César, pois o Senado acreditou que César havia se tornado um deus.

O quarto livro diz respeito a abril (aprilis, -is, s. m.) que, a princípio, era o segundo mês do ano romano. Cultuava-se a deusa Vênus, deusa da vegetação e da fertilidade.

Segundo Pierre Grimal (2000, p. 466):

Vênus (Venus), antiga divindade latina, possuía um santuário próximo de Árdea, edificado em data anterior à fundação de Roma. Considerada durante muito tempo como protetora da vegetação e dos jardins, é agora encarada por certos autores como um gênio mediador da oração. Mas tudo isto é muito incerto. É assimilada, no século II a. C., à Afrodite grega. A Gens Iulia, que pretendia descender de Enéias, tomava Vênus como ancestral.

Na sua obra, Ovídio apresenta duas etimologias para o nome do mês, sem, no entanto, dizer qual será a abonada por ele. Numa primeira explicação, o poeta das Metamorfoses refere-se à deusa grega Afrodite, cujo nome se prende à espuma do mar, o que teria dado origem à forma aprilis (versos 61-62).

Sed Vereris mensem Graio sermone notatum

Auguror; a spumis est dea dicta maris. (v. 61-62)

Eu (Ovídio) acredito que o mês de Vênus está registrado na língua grega. A deusa foi denominada a partir da espuma do mar.

A segunda explicação etimológica utilizada pelo poeta é de que o nome de abril provém do verbo da quarta conjugação latina aperio, -is, -ire, perui, petum, que na sua primeira acepção significa "abrir"; os antigos gramáticos criaram a forma aperelis < aperio, para explicar o nome do mês Aprilis. Segundo Ovídio, neste mês a primavera abre a natureza, fazendo-a desabrochar (v. 87-90):

Nam, quia ver aperit tunc omnia, densaque cedit

Frigoris asperitas, foetaque terra patet,

Aprilem memorant ab aperto tempore dictum;

Quem Vênus injecta vindicat alma manu. 
$\mathrm{Na}$ verdade, porque a primavera abre então todas as coisas, e a aspereza densa do inverno cai e a terra desfigurada se abre. Aqueles lembram que o mês de abril é chamado a partir do tempo desabrochado, o qual a venerável Vênus reivindica com a mão colocada em cima.

Etimologicamente, os romanos associavam a ação de abrir ao mês em que a natureza se abre, floresce, desponta, mostra-se para oferecer ao mundo suas propriedades mágicas. Logo, nesta segunda acepção, o mês de abril origina-se do verbo aperire.

Há de se notar também que neste mês (abril) abriu-se para os romanos mais uma vitória. Júlio César vence os pompeianos em 46 A. C. na região denominada Tapso. Neste mês, também, abre-se aos romanos a vitória de Augusto sobre Marco Antonio, e o título militar de Imperador é recebido por Augusto. Neste mês, também, são homenageadas as deusas Flora, Vesta e Ceres.

O quinto mês do ano era maio (Maius mensis, em latim). No início do poema, Ovídio apresenta uma discussão sobre o nome do mês, sugerindo-nos três etimologias; primeiramente, o nome do mês está relacionado com a deusa Maia, mãe de Mercúrio.

Segundo Pierre Grimal (2000, p. 289):

Existia, em Roma, em tempos muito antigos, uma deusa Maia que, sem dúvida, não teve na origem qualquer relação com a Maia grega. Aparece por vezes como paredro de Vulcano, deus do fogo. O mês de maio era-lhe especialmente consagrado. Após a introdução do helenismo, foi identificada com a sua homônima, e tornou-se a mãe de Mercúrio.

Outra etimologia descrita pelo poeta, mas sem tecer opinião de qual seria a etimologia correta, refere-se ao fato de que o mês era também dedicado aos antepassados: aos Maiores, ou seja, aos mais velhos. Havia, neste mês, uma festa dedicada aos que já haviam partido: os Lêmures, almas dos mortos que aguardavam o descanso eterno. Acreditava-se ser esta a origem do nome do mês.

Os Fastos de Ovídio terminam com as referências às festas religiosas realizadas em junho, Iunius mensis, dedicada à deusa Juno.

Juno é a deusa romana assimilada a Hera. Na origem, e na tradição romana, ela personifica o ciclo lunar e figura na Tríade inicialmente honrada no Quirinal, depois no Capitólio, e que engloba Júpiter, Juno e Minerva. (GRIMAL, 2000, p. 260). 
Como primeira etimologia, podemos atestar que se o mês anterior era dedicado aos maiores /Maius (aos mais velhos), nada estranho que o mês de junho se originasse de iuniores / Iunius (jovens). Segundo os romanos, o mês de junho provém de iuvenis $>$ jovem. Outra hipótese levantada sobre a etimologia deste mês refere-se ao verbo iungo (jungo), - is, iungere, -xi, - ctum, da terceira conjugação latina; juntar, unir, reunir, pois foi neste mês que, depois de muitas guerras, os romanos se juntaram aos sabinos após o rapto da sabinas, unindo-se numa só nação, num só corpo. Nesta acepção, junho viria do verbo iungere. Cultuava-se e homenageava-se também neste mês a deusa romana Vesta de caráter muito arcaico que presidia ao fogo sagrado. Mantinha-o acesso e assim unia a alma da cidade e o ânimo dos romanos.

A respeito dos outros seis livros (julho a dezembro) que comporiam a obra ovidiana, paira uma incógnita, como tantas que circundam a vida do vates Ovídio; ou foram perdidos ou destruídos ou, talvez, nunca foram escritos. Não há, na literatura latina, nenhuma menção a eles. O que se sabe de concreto é que no ano 8 de nossa era, o poeta foi banido de Roma para o último reduto do império romano, o Pontus Euxinus, lá falecendo no ano 18/17, sem ter obtido o perdão imperial.

\section{A festa de Ana Perena}

Segundo Grimal (2000, p. 24-25):

Ana Perena divindade romana muito antiga, honrada num bosque sagrado, situado mesmo ao norte de Roma, na Via Flamínia. Representam-na com traços de uma velha mulher. Quando se deu a Secessão da plebe no Monte Sagrado, como as provisões fossem insuficientes, Ana Perena terá feito uns bolos que todos os dias vendia ao povo, evitando assim a fome. Por esta razão lhe terão prestado honras divinas após a cessação dos motins políticos e a reentrada da plebe em Roma.

Dos versos 523 a 544, o poeta Ovídio descreve, com imensa plasticidade, a festa popular e os rituais dedicados à deusa Ana Perena. A descrição inicia-se com a datação da festa, através de uma invocação ao Tibre, rio que banha a cidade de Roma.

Idibus est Annae festum geniale Perennae

Haud procul a ripis, aduena Tibri, tuis. (v. 523-4) 
Nos idos (15 de março) há a festa popular de Ana Perena, não muito longe de tuas margens, ó (rio) Tibre estrangeiro.

No verso 524, o poeta adjetiva o rio Tiber, chamando-o adue$n a$, estrangeiro, alusão feita à foz do rio que nasce fora dos limites da Urbe, na região da Etrúria, não muito longe de Roma.

Nesta festa popular dedicada à deusa Ana Perena, segundo o relato do autor, nenhuma restrição era imposta à plebs. Dos versos 525 ao 530, há a descrição de todo o ritual utilizado nos festejos pelos habitantes que aderiram à festa.

Plebs venit, ac virides passim disjecta per herbas

Potat et accumbit cum pare quisque sua.

Sub Jove pars durat: pauci tentoria ponunt:

Sunt, quibus e ramis frondea facta casa est:

Pars sibi pro rigidis calamos statuere columnis,

Desuper extentas imposuere togas.

A plebe chega e espalhada por aqui e por ali, sobre as verdes relvas, bebe e deita-se cada um com sua companheira. Uma parte da multidão fica ao ar livre. Poucos armam tendas (tentoria, v. 527) Existem aqueles que constroem uma cabana (casa, v. 528) com ramos de folhagens. Parte da plebe fincou caniços (columnis, v. 529) em lugar de rígidas colunas e colocou, por cima, as togas esticadas.

Continuando sua descrição, o poeta nos relata as consequências da festa ao ar livre e do excesso de vinho, nos versos 531-2.

Sole tamen vinoque calent: annosque precantur,

Quot sumant cythos; ad numerumque bibunt.

Todavia, por causa do vinho e do sol, eles se esquentam e suplicam tantos anos de vida quanto o número das taças que bebem e saúdam esse número.

$\mathrm{O}$ poeta, como personagem onipresente à festa, dirige-se ao possível leitor de sua obra e adverte-o, v. 533-4:

Invenies illic, qui Nestoris ebibat annos.

Quae sit per calices facta Sibylla suos.

Neste lugar, encontrarás (ó leitor) aquele que bebe à idade, de Nestor e, aquela que se torna Sibila pelos seus cálices.

Os versos analisados neste artigo são a descrição de uma festa realizada, segundo o poeta, nos idos de março (v. 523). Os enunciados relatam ocorrências simultâneas e cronologicamente dispostas no texto através dos verbos uenit (v. 525); potat (v. 526); accumbit (v. 
526); durat (v. 527); e ponunt (v. 527). A descrição dos fatos feita pelo poeta revela-nos as características de uma festa popular festum geniale (v. 523), inscrita num certo momento estático do tempo e que ocorre simultaneamente num lugar concreto e delimitado nos idos (v. 534) ou seja, no dia 15 de março não muito longe das margens do rio Tibre - Haud procul a ripis, aduena Tibri, tuis (v. 534).

O cortejo formado pela plebs, que cambaleia, por causa do vinho, ao retornar dos festejos em honra à deusa Ana Perena, desperta a multidão que se encontra no caminho obvia turba (v. 540); ou melhor, nas ruas da Roma antiga a evocação do adjetivo fortunatos (v. 540), ou seja, felizes, uma alusão à felicidade demonstrada pelos participantes da festa.

Pars sibi pro rigidis calamos statuere columnis,

Desuper extentas imposuere togas. (v. 529-530)

Parte da plebe fincou caniços em lugar de rígidas colunas e colocou, por cima, as togas esticadas.

O poeta, em se tratando de Ovídio, é mais apropriado que se diga vates o poeta iluminado que nos versos 541-2 se torna sujeito desta descrição, menciona que ele próprio presencia o estado etílico da plebs. Interfere na descrição, relatando uma das últimas cenas do cortejo: senem potum pota trahebat anus (v. 5420)“ uma velha embriagada arrasta um velho igualmente embriagado"

Ovídio explica que não sabe, com precisão, a origem desta deusa que errat (v. 543) no meio de incertezas e que tudo que se fala é uma fabula (v. 544), uma história, uma narração fictícia, todavia defende a ideia de que em seu discurso não deve silenciar sobre esta deusa à qual são dedicados festejos populares anuais sempre na mesma data e local.

Os versos 535-8 sugerem-nos a coreografia e a musicalidade, que, segundo o autor, foram apreendidas pela plebs nos teatros (v. 535) e que, segundo a mitologia, são as canções obscenas cantadas na festa de Ana Perena:

Illic et cantant, quidquid didicere theatris;

Et jactant faciles ad sua verba manus;

Et ducunt posito duras cratere choreas,

Cultaque diffusis saltat amica comis. 
[...] também, nesse lugar, cantam aquilo que aprenderam no teatro. Agitam suas mãos ágeis conforme os seus versos e realizam danças rudes abandonando as taças, e a companheira ornamentada dança com os cabelos soltos.

\section{Conclusã̃o}

Nos Fastos, escritos em seis livros, Ovídio nos proporciona uma visão privilegiada de fatos, lendas, tradições, rituais existentes em Roma, dos seus primórdios ao governo de Augusto. São narrações de fatos até mesmo esquecidos ou ignorados pelos romanos na época da publicação desses livros.

O levantamento, feito pelo poeta, nos pergaminhos e/ou códices existentes em bibliotecas romanas, trouxe à visão, não só dos leitores de sua época, mas também aos da Idade Média, o conhecimento sociocultural-religioso de uma fase da história romana. Apesar do banimento de Ovídio, sua obra não sofreu, da parte do imperador Augusto, nenhum ato de violência. Assim, ela chegou até os dias de hoje, permitindo que seus textos sejam pesquisados pelos amantes da língua latina que reconhecem no poeta Ovídio os traços indeléveis de um gênio criador que, vivendo na Roma clássica, gravou seu nome entre os poetas da época, cônscio do valor de seus versos. 


\section{DEPARTAMENTO DE LETRAS}

\section{REFERÊNCIAS}

BAYET, Jean. Littérature latine. 10. éd. Paris: Armand Colin, 1962.

CARCOPINO, J. Roma no apogeu do Império. Tradução de H. Feist. São Paulo: Companhia das Letras/ Círculo do Livro, 1990.

CARDOSO, Zélia de Almeida. Festas romanas: da época dos reis ao advento do cristianismo. Palestra proferida no VI Congresso da SBEC. Rio de Janeiro: UFRJ, 2005.

CORREIA, Natália \& FERREIRA, David Mourão. Ars amatoria. São Paulo: Ars Poética, 1992.

D'ONOFRIO, Salvatore. Literatura ocidental: Autores e obras fundamentais. São Paulo: Ática, 2007.

ELIADE, M. História das crenças e das idéias religiosas. Tradução de R. C. Lacerda. Rio de Janeiro: Jorge Zahar, 1979, v. 1, tomo 2.

FARIA, Ernesto. Fonética histórica do latim. Rio de Janeiro: Acadêmica, 1970.

dêmica, 1958.

. Gramática superior da língua latina. Rio de Janeiro: Aca-

GAFFIOT, F. Dictionnaire latin-français. Paris: Hachette, 1934.

GRIMAL, Pierre. Dicionário da mitologia grega e romana. 4. ed. Tradução de Victor Jabouille. Rio de Janeiro: Bertand Brasil, 2000.

KURY, Mário da Gama. Dicionário de mitologia grega romana. Rio de Janeiro: Jorge Zahar, 1990.

LOPES, Eliana da Cunha. Heroides XVI e XVII de Ovídio: um hino de amor. Dissertação de mestrado em língua e literatura latinas. Rio de Janeiro: UFRJ/ Faculdade de Letras, 1993.

MAROUZEAU, J. Dictionnaire culturel de mytthologie grécromaine. Paris: Éditions Nathan, 1992.

MARTIN, René \& GAILLARD, Jacques. Les genres litéraires à Rome. Paris: Éditions Nathan, 1990.

OVID. Fasti. With na englis ranslation by James George Frazer. Cambridge: Harvard University Press, 1996. 


\section{FACULdADE de FormaÇÃo de PROFESSORES}

OVIDE. Les Fastes. Tradution, introdution et notes par E. Ripert. Paris: Garnier, 1934.

. Les Fastes. Tradution et note par Henri le Bonniec. Préface de Augusto Fraschetti. Paris: Les Belles Lettres, 1990.

RIPERT, E. Ovide poete de I'amour, des dieux et de exil. Paris: Armand Colin, 1921.

SARAIVA, F. R. dos Santos. Novíssimo dicionário latino-português 11. ed. Rio de Janeiro: Garnier, 2000. 